\title{
LA LUCHA DE LAS MUJERES MIGRANTES HAITIANAS POR LA SEGURIDAD CIUDADANA
}

BRIDGET WOODING*

\section{Resumen}

Hace más de una década, las y los estudiosos de las migraciones en América Latina y el Caribe han señalado un nuevo giro en las relaciones transfronterizas internacionales terrestres como espacios de convivencia y cooperación, las cuales han registrado menos conflicto que antes. Sin embargo, aunque la frontera dominico-haitiana se encuentra en plena transición, sigue ostentando niveles de violencia dirigida particularmente a grupos vulnerables y, en consecuencia, viciando la seguridad ciudadana. Este artículo propone un análisis de la violencia contra las mujeres migrantes haitianas que se encuentran en tránsito y desplazadas hacia la franja fronteriza dominico-haitiana. Si bien es urgente un marco legislativo más favorable tanto en el país de origen como en el de destino, también es apremiante una opinión pública más sensibilizada en estos temas; es así que se hace hincapié en los roles y responsabilidades de dos de los actores fundamentales que se enfrentan en esta zona: las mismas mujeres migrantes, como sujetos de derechos, y las autoridades competentes, como garantes de estos derechos. Se subraya, asimismo, la necesidad imperativa de un cambio radical en las prácticas actuales que toleran - sin mayor ruido en la isla y más allá- las violaciones a los derechos humanos que tienen lugar en esta frontera, señalando posibles pistas de acción para actores clave y aliados de estas mujeres en su proceso migratorio.

Palabras clave: migración, frontera dominico-haitiana, derechos humanos, mujeres vulnerables, relaciones transfronterizas.

${ }^{\star}$ Observatorio Migrantes del Caribe, CIES-UNIBE. 


\begin{abstract}
Over a decade ago, migration scholars in Latin America and the Caribbean pointed to a change in international terrestrial cross-border relations as spaces of coexistence and cooperation, stating they now experience less conflict than before. However, although the Dominican-Haitian border is undergoing a thorough transition, it still shows a degree of violence aimed at specific vulnerable groups, all of which affects public security. This paper addresses the violence committed against Haitian migrant women who are in transiting the DominicanHaitian border or have been displaced. While a more favorable legislative framework in both the country of origin and destination is urgent, there is also a dire need for a more sensitive public outlook on these issues in order to focus on the roles and responsibilities of two of the key players in this area: the migrant women themselves as holders of rights, and the competent authorities as guarantors of these rights. There is an imperative need for a radical change in current practices that tolerate, without much disruption in the island or beyond, the violations of human rights that take place along this border. I also suggest possible action strategies for key actors and supporters of these women in their migration process.
\end{abstract}

Keywords: Dominican-Haitian border, human rights, migration, vulnerable women. 


\section{INTRODUCCIÓN}

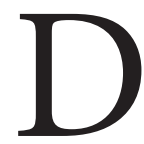

esde finales del siglo pasado, la llamada nueva visión de la frontera (FLACSO RD, 2002; Lozano y Wooding, 2008) afirma que la cooperación ha de caracterizar la frontera, y con ello se aleja de la conceptualización anterior de estos lindes como zonas tradicionales de conflicto en América Latina y el Caribe (Castor, 1988; Lozano, 1992). Sin embargo, esta retórica — antes revisionista, y ahora ampliamente aceptada - no forzosamente se refleja en los hechos, de manera que algunos estudiosos hablan más bien de zonas en transición (Dilla, 2007) o con conflictos de baja intensidad (Murray, 2010).

La frontera dominico-haitiana se abrió oficialmente hace 25 años, tras la caída de la dictadura de Duvalier en Haití, en 1986 (FLACSO/ INESA, 2003). No obstante, en momentos de tensión política o de crisis de otra índole, tienden a ser instrumentalizados tanto el cierre oficial como la apertura de algunos de sus puntos. Entre 2010 y 2011, la convivencia de migrantes en tránsito y los moradores de dicha frontera ha sido sacudida por tres hitos:

- El terremoto de enero de 2010 tuvo como secuela un desplazamiento masivo en varias direcciones, incluida la frontera. Muchas de las personas desplazadas fueron acogidas en casas anfitrionas, con resultados mixtos para los derechos de las personas sujetas a esta migración forzada (ACNUR, 2010);

- Desde octubre del mismo año, el brote de cólera afectó todos los departamentos de Haití y cruzó, como era de esperarse, hacia República Dominicana. A comienzos de 2011, las autoridades dominicanas aumentaron el ritmo de repatriaciones de haitianos hacia su país, alegando que se trataba de una medida de control sanitario, aunque meses más tarde estas mismas medidas fueron revertidas sin que se contuviera la enfermedad. Durante el tiempo de más control en la frontera, una consecuencia inesperada fue que las mujeres migrantes tuvieron que hacer aún más uso del cruce informal, con todos los peligros que conlleva "pasar por el monte", y 
- La violencia desatada entre abril y mayo de 2011 tras las elecciones presidenciales y parlamentarias en Haití tuvo efectos en su franja fronteriza central, causando una baja en la presencia de las autoridades haitianas y en su capacidad operativa, ya que varias de sus instalaciones fueron saboteadas en Belladère y los funcionarios haitianos emprendieron la fuga. Como resultado de este pico de violencia en Haití, se observó aún más presión sobre algunos servicios sociales del lado dominicano, especialmente en lo referente a salud pública (Petrozziello y Wooding, 2011).

A pesar de un contexto aún más volátil de lo normal en la frontera, hoy en día, y de cara a las dinámicas migratorias, es necesario aceptar que no se ha prestado suficiente atención a esta realidad en la que, como siempre, algunos de los grupos más vulnerables pueden estar particularmente desafiados por estos nuevos acontecimientos. Si bien las mujeres haitianas desplazadas en los llamados tent cities - los campamentos de Puerto Príncipe y sus alrededores-, han recibido mucha atención debido al auge de los estudios relacionados con la violencia contra la mujer, en particular la violencia sexual, no se ha puesto la lupa sobre una situación cada vez más compleja en la frontera (InterAction, 2010; IJDH et al., 2010; Refugees International, 2010; Schuller, 2010; Toupin, 2010). No es casual que suceda lo mismo en República Dominicana que en Haití en lo que se refiere a quién puede recibir atención mediática: es más viable que se dé una mirada más profunda en Santo Domingo (su capital) que en una frontera lejana y abandonada a su suerte.

El 12 de julio de 2011, la joven Rooldine Lindor, estudiante universitaria de nacionalidad haitiana, fue violada y asesinada en Santo Domingo del Este. Aunque la tragedia hubiera podido pasar inadvertida dado el marco de un aumento general de la delincuencia y la criminalidad en República Dominicana, se suscitó una reacción inesperada de indignación por la comunidad haitiana en ese país, así como en los más altos niveles en Haití y hasta en los medios internacionales. ${ }^{1}$ Además, a pesar

1. El embajador dominicano en Haití se vio en la necesidad de sacar una nota de prensa el 15 de julio de 2011, deplorando el acontecimiento y garantizando la persecución judicial de los presuntos perpetradores. 
de estar en proceso la conformación de su administración, el presidente Martelly no se quedó atrás y dio seguimiento al caso al apoyar la visita a Santo Domingo de parlamentarios haitianos que interactuaron con sus homólogos y con el Poder Judicial sobre el caso de Rooldine Lindor. ${ }^{2}$

La prensa haitiana reseñó la muerte como "una bofetada" a los haitianos en República Dominicana; por su parte, grupos de feministas y otros actores de la sociedad civil dominicana se han solidarizado con la comunidad estudiantil haitiana, mostrándose alarmados por lo ocurrido. Algunos analistas consideran que el asesinato de esta extranjera joven podría tener secuelas semejantes a las de la muerte de la inmigrante dominicana Lucrecia Pérez, en Madrid, hace casi dos décadas, cuando dicho acontecimiento logró un movimiento sostenido en pro de los derechos de las mujeres inmigrantes en España, situación que no se había dado anteriormente. ${ }^{3}$

Sin embargo, hay otros contextos sociales y geográficos en la isla que comparten Haití y República Dominicana — la segunda más grande del Caribe-, donde los derechos de las mujeres migrantes haitianas son violados diariamente. ¿Por qué la violencia contra las mujeres migrantes ${ }^{4}$ en estos otros escenarios no recibe la atención debida? ¿Es porque las migrantes no viven en una metrópoli, sino en los intersticios de los dos países que conforman la isla? ¿Es porque ocupan un rango más bajo en la estratificación social? ¿Es porque no tienen un estatus migratorio positivo? ¿Es por el color de su piel? Este trabajo procura sacar de la invisibilidad a las mujeres que viven y trabajan en situaciones de alto riesgo en cuanto a su seguridad ciudadana, al tiempo que da cuenta de razones socioculturales arraigadas por las que las mujeres haitianas aceptan que esta gama de violencia en su contra puede ser parte de su cotidianidad.

2. Liriano, Jhonatan, "Diputados haitianos visitan el Congreso Nacional”, en $\mathcal{E}$ l Caribe, 2 Septiembre 2011; disponible en http://www.elcaribe.com.do/site/pais/nacionales/286658diputados-haitianos-visitan-congreso-nacional-html.

3. Para el aniversario de los tres meses de la muerte de Lindor, las organizaciones representativas de los estudiantes haitianos buscan convocar a una conmemoración, apelando para estos fines a sus aliados de la sociedad dominicana.

4. El término "migrantes" se deriva del uso de "trabajadoras migrantes" en el CEDAW Recomendación general No. 26 sobre las trabajadoras migrantes, ratificada en 2008; disponible en http://www2.ohchr.org/english/bodies/cedaw/docs/GR_26_on_women_ migrant_workers_sp.pdf. 
El caso que nos ocupa es el de la frontera dominico-haitiana, siendo nuestro escenario específico el del binomio de las ciudades Comendador (en la provincia de Elías Piña, del lado dominicano) y Belladère (en el departamento del Plateau Central, del lado haitiano). ${ }^{5}$

Las fronteras son lugares complejos en los que opera una multitud de actores distintos, y en los que hay varios intereses en juego. En la frontera dominico-haitiana, las mujeres migrantes navegan entre comerciantes y cobradores, guardias, traficantes, tratantes, proxenetas, funcionarios, familias anfitrionas, empleadores(as), así como con sus propias parejas y familias. En esta variedad de contextos, las migrantes, mujeres en tránsito y desplazadas, se encuentran expuestas a varios tipos de violencia. Ellas vienen de un país marcado por la pobreza extrema, expuestas a una violencia estructural que desencadena otros tipos de violencia en su vida, como puede ser la violencia doméstica, física o sexual (Farmer, 2003). Cuando migran se ven expuestas a otros tipos de violencia según la situación en que se encuentren, ya sea en el monte, en el mercado o en la kay madam ${ }^{6}$ donde se exhibe la "interseccionalidad" — concepto desarrollado sobre todo por activistas feministas, que analiza la discriminación a base de diferentes ejes de identidad como pueden ser el género, la clase social, el estatus migratorio o la etnia, entre otros- (CAWN, 2010).

Llama la atención la invisibilidad de las mujeres migrantes en este entorno en que pueden ser repatriadas a Haití sin respetar el debido proceso ni el reconocimiento del protocolo binacional que rige en la materia desde 1999 o, en el peor de los casos, pueden ser asesinadas, sin aparecer en ningún registro del país. Hay una serie de factores que confluyen para mantener en la impunidad a los perpetradores de la violencia (hombres en su mayoría, aunque no exclusivamente), sea en el cruce formal o informal, en el ámbito familiar, en la esfera de trabajo en los hogares de

5. Este artículo se basa en los hallazgos de una investigación reciente (2011) ejecutada por el Observatorio Migrantes del Caribe (OBMICA, CIES-UNIBE/FLACSO), de las autoras Allison Petrozziello y Bridget Wooding, comisionada por la ONG dominicana "Colectiva Mujer y Salud", y apoyada por la AECID y la OIM titulada: Fanm nan fwontye, fanm toupatou: Una mirada a la violencia contra las mujeres migrantes, en tránsito y desplazadas en la frontera dominico-haitiana (Elías Piña/ Belladère).

6. El término kay madam en creole haitiano se refiere a la casa de familia o, literalmente, "casa de la señora", donde muchas migrantes encuentran empleo al llegar a territorio dominicano. 
terceros, en los prostíbulos de la zona o en el mercado fronterizo de lunes $y$ viernes en Comendador.

Más allá de un marco legislativo favorable, indudablemente necesario tanto en el país de origen como en el de destino, ${ }^{7}$ y de una opinión pública más sensibilizada hacia estos temas, este artículo hace hincapié en los roles y responsabilidades de dos de los actores fundamentales que se enfrentan en esta panorámica: principalmente, las mismas mujeres migrantes como sujetos de derechos y con capacidades destacables, así como las autoridades competentes, que tendrían que garantizar sus derechos. También se subraya aquí la necesidad imperativa de un cambio radical en las prácticas actuales que toleran estas violaciones, señalando posibles pistas de acción para algunos actores clave, con énfasis en el quehacer de aliados con que pueden contar estas mujeres en su trayectoria.

\section{CONTEXTO}

Las mujeres migrantes haitianas, así como las desplazadas y las que están en tránsito en la zona fronteriza dominico-haitiana, se encuentran en una situación especialmente vulnerable ante la violencia contra las mujeres (VCM). Muchas migran de forma espontánea buscando mejorar su situación de vida; otras han sido desplazadas por el terremoto de enero de 2010 y, más recientemente, por la violencia postelectoral desatada entre abril y mayo de $2011 .{ }^{8}$ En la región hay altos niveles normalizados de violencia contra las mujeres, de varios tipos: violencia física, sexual, económica, verbal, psicológica, etcétera; además de altos riesgos de tráfico ilícito de personas, incluyendo la trata con fines de trabajo sexual forzado.

7. La República Dominicana tiene una legislación relativamente robusta en cuanto a la violencia contra la mujer, mientras que, en Haití, el Ministerio del Estatus de la Mujer y sus Derechos (MCFDF, por sus siglas en francés) presentó un anteproyecto a mediados de 2011 que, de ser aprobado, daría a Haití una legislación muy avanzada en la materia. Hay que reconocer, sin embargo, que tanto en Haití como en República Dominicana los retos son mayores cuando de aplicación se trata.

8. La llamada "feminización de las migraciones" se refiere no forzosamente a que las mujeres están migrando más que los hombres (aunque puede ser el caso en algunos contextos), sino más bien al hecho de que migran muchas veces por su cuenta y como el proveedor principal de la familia (UN-INSTRAW, 2008). 
El mercado fronterizo de Comendador es un punto importante de comercio para muchas mujeres haitianas que, a la vez, las expone a situaciones de "macuteo". 9 También se han detectado situaciones propicias a la VCM en casas anfitrionas donde se hospedan mujeres y niñas desplazadas tras el terremoto en Haití, y casas empleadoras de trabajadoras domésticas migrantes, entre otras. Finalmente, los brotes de cólera (2010-2011) han llevado a las autoridades a cerrar la frontera en varias ocasiones y a segregar a las y los vendedores haitianos de los dominicanos en un mercado provisional en El Carrizal, todo esto como medida de salud pública. Este hecho provocó que se elevara el número de mujeres que cruzaban la frontera por puntos no oficiales, donde se vieron expuestas a robo, violencia sexual y, en algunos casos extremos, homicidio/ femicidio.

Sin embargo, las tasas de denuncia de la VCM interpuestas por las sobrevivientes haitianas son muy bajas, tanto por la falta de conocimiento de sus derechos como por el funcionamiento inadecuado de los servicios de atención en la frontera del lado dominicano y por la escasez de estos servicios en la frontera haitiana. Desde la perspectiva institucional, hay una marcada falta de redes de apoyo, de servicios de salud en general y de atención a trastornos postraumáticos. Sumadas a esta situación, están la insuficiente atención a los derechos de las mujeres a nivel local y nacional, actitudes discriminatorias y xenófobas por parte de algunas autoridades y prestadoras de servicios, así como una impunidad generalizada hacia los perpetradores.

\section{METODOLOGÍA DEL ESTUDIO}

En el estudio se emplearon métodos cualitativos de investigación, con el objetivo de generar una comprensión profunda de las diferentes situaciones de VCM. Se hizo una revisión documental de la literatura relevante, tanto teórica como empírica, previa al trabajo de campo, que se llevó a cabo durante la segunda quincena de mayo de 2011. Para ello

9. Jerga popular en República Dominicana para denotar extorsión por parte de las autoridades. 
colaboraron estrechamente las promotoras de la organización no gubernamental (ONG) dominicana denominada Colectiva Mujer y Salud (CMS) - que tras el terremoto en Haití ha hecho un esfuerzo especial por extender sus servicios a la población en cuestión- y el equipo de investigación del Observatorio Migrantes del Caribe (OBMICA) - que cuenta con investigadoras multilingües, especializadas en temas de género, migración, salud sexual y reproductiva y desarrollo-.

Durante el trabajo de campo, el equipo de investigación de OBMICA llevó a cabo las siguientes actividades:

- 28 entrevistas con actores clave, en especial las autoridades locales, instituciones y organizaciones que prestan servicios de atención, orientación, prevención y apoyo a las sobrevivientes de violencia. De estas entrevistas, 20 fueron con actores de Elías Piña, una con actores de Jimaní, una con actores de San Juan de la Maguana y seis con actores de Belladère;

- 18 entrevistas a profundidad, semiestructuradas, con mujeres y niñas haitianas con experiencia y/o conocimiento de VCM; 16 de estas entrevistas fueron realizadas en creole y dos en español, con mujeres y niñas residentes o en tránsito en Comendador. De las 18 mujeres y niñas, nueve son migrantes residentes en Comendador desde antes del terremoto, siete son mujeres desplazadas a causa del terremoto y dos son mujeres en tránsito que viven en Haití y vienen a vender en el mercado fronterizo. Ocho de las mujeres entrevistadas son trabajadoras domésticas, cinco son vendedoras en el mercado, cuatro son hijas de crianza y una es ama de casa/usuaria del hospital;

- Trabajo con dos grupos focales de mujeres haitianas sobrevivientes de VCM; en cada uno de estos grupos participaron 12 mujeres. Las participantes del primer grupo eran migrantes procedentes de Belladère, Lascahobas, Mibalen y zonas aledañas; viven en La Pastilla y Galindo, y se dedican a vender en el mercado y a trabajar en casas de familia. Las del segundo grupo eran casi todas mujeres desplazadas tras el terremoto en Puerto Príncipe, que manifestaron la precariedad en que viven: lavan ropa ajena o "echan jornadas" en el trabajo agrícola por $\mathrm{RD} \$ 50 /$ día; casi todas residen en el barrio Los Corositos, y 
- Visitas de observación al mercado fronterizo, el punto de cruce fronterizo en Carrizal y un lugar de diversión nocturna en que laboran varias trabajadoras sexuales haitianas.

Algunas de las mujeres participantes fueron identificadas a través de contactos previos de la CMS; otras fueron identificadas a través de la técnica "bola de nieve", en que unas personas referían a otras. Las mujeres que fueron entrevistadas se seleccionaron a través de la estrategia de investigación cualitativa purposeful selection (Maxwell, 2005:88), en la que se escogen ciertas actividades, personas y lugares - en este caso, mujeres que trabajan en el mercado o en casas de familia, niñas desplazadas que son "hijas de crianza" - que proporcionen información que no necesariamente se pueda conseguir de manera aleatoria, especialmente sobre un tema sensible como puede ser el de VCM. Todos los nombres usados en este informe fueron cambiados para proteger la identidad de las entrevistadas y no agravar las situaciones de violencia a que están expuestas.

En la última parte de la investigación (antes de elaborar el informe final) se celebró un taller de "devolución de los hallazgos principales" con miras a validar el informe y recoger sugerencias que potenciaran el seguimiento de la investigación. En el taller participaron 22 actores locales, tanto de Elías Piña como de Belladère, y 20 mujeres haitianas. En los meses de julio y agosto de 2011, las investigadoras llevaron a cabo dos talleres de capacitación con mujeres haitianas. En estos talleres se confirmaron los hallazgos, a la vez que se empezó a elaborar una agenda mínima para mejorar la situación de violencia en el nuevo mercado a construirse en El Carrizal. Paralelamente, se llevaron a cabo dos reuniones de trabajo con autoridades y actores locales relevantes en Elías Piña para detectar los casos de violencia en el mercado y en el cruce fronterizo, identificar puntos de acción y fortalecer el sistema de referencia en casos de violencia.

La mayoría de las entrevistas, así como los trabajos con los dos grupos focales, fueron grabados en archivos MP3; posteriormente, se hicieron transcripciones parciales y resúmenes en español para facilitar el análisis de la información producida. Se compararon los hallazgos con 
los de otros estudios afines, para alcanzar una mejor comprensión de la problemática estudiada. Originalmente, se había contemplado hacer una visita al pueblo de Belladère, Arrondissement de Lascahobas, departamento Plateau Central de Haití, para complementar las informaciones levantadas desde una perspectiva transfronteriza; sin embargo, no se pudo cruzar la frontera durante el periodo de trabajo de campo debido a los brotes de violencia liderados por activistas políticos que disputaban los resultados de las elecciones recientes en ese lugar. En el mes anterior al trabajo de campo, ellos prendieron fuego al Ayuntamiento y la Fiscalía de Belladère, y a la casa antigua del hospital, donde murieron dos médicos haitianos y sus hijos. Para compensar esta limitación, se invitó a varios actores clave de la sociedad civil de Belladère a Comendador; seis de ellos fueron entrevistados. No se pudo localizar a ningún representante de las organizaciones del Estado en Belladère; al parecer, la mayoría se había fugado a Puerto Príncipe, hecho que dificulta seriamente el acceso de las mujeres en tránsito a los servicios de atención en casos de violencia.

También se hizo un esfuerzo especial por identificar y localizar a mujeres migrantes que hubieran sido víctimas de trata o trabajadoras sexuales. Desafortunadamente, el acceso a estas poblaciones fue limitado, así que la información recolectada sobre estos temas se limita a información relatada por otras personas conocedoras de la temática.

\section{VULNERABILIDADES Y CAPACIDADES DE LAS MUJERES MIGRANTES HAITIANAS}

Los perfiles de las personas entrevistadas incluyen mujeres comerciantes transfronterizas y transitorias en el mercado fronterizo de Comendador; mujeres desplazadas tras el terremoto de enero de 2010, especialmente las que están alojadas en casas anfitrionas; trabajadoras domésticas remuneradas; y niñas desplazadas tras el terremoto de enero de 2010, que han sido acogidas como "hijas de crianza".

Las mujeres migrantes perfiladas tienen muy bajos ingresos. Por ejemplo, las trabajadoras domésticas ganan $\mathrm{RD} \$ 1000-\mathrm{RD} \$ 1500$ por mes, y muchas dicen que están pasando hambre. Algunas muestran 
síntomas de padecer problemas de salud (por ejemplo, delgadez extrema, bocio) y varias sufren de traumas emocionales debido a sus vivencias en el terremoto y otras violencias.

Como suele ocurrir en las fronteras terrestres, hay mucho movimiento entre Haití y República Dominicana (incluyendo drogas, armas $\mathrm{y}$ contrabando en general). En estas dinámicas migratorias puede haber la tendencia a subestimar las dificultades que enfrentan las personas en el cruce, tanto formal como informal, sobre todo por el sesgo de género cuando se trata de la mujer migrante haitiana.

Si bien el tráfico ilícito de personas es un delito punible, no necesariamente se puede considerar una violación de derechos humanos ni VCM de por sí, ya que muchas escogen pagar los servicios de traficantes o "el macuteo" a los funcionarios en ausencia de conocimiento o acceso a opciones legales de migración. No obstante, la clandestinidad en que operan los traficantes crea condiciones propicias para que se pueda ejercer otras violencias contra las mujeres migrantes, tales como el engaño de buscones y choferes, violación sexual en el camino ${ }^{10}$ y la trata de personas. Esto contradice la observación de Dilla, que afirma que "para estos tráficos la frontera es sólo un lugar de paso sin más implicaciones que la tensión policíaca y militar que generan” (Dilla, 2008:31). Si se toman en cuenta los riesgos y la desprotección que supone para las mujeres migrantes el tráfico de personas, se entiende que la frontera es un lugar que da paso a una gama de violaciones de sus derechos humanos. ${ }^{11}$

En este contexto, las mujeres y niñas tienen capacidad de elegir entre diferentes opciones, mientras que sus acciones están circunscritas por un espectro amplio de vulnerabilidades. Sin embargo, las tácticas que emplean no logran cambiar radicalmente sus circunstancias ni logran hacer clara su situación ante quienes deben de ser los garantes de

10. Cassandra es una joven que canceló sus planes de perseguir su sueño capitalino. Ella nos contó de los abusos de un traficante que vivía en su barrio: "Hay un hombre que venía con una mujer para la capital y cuando llegó a mitad de camino la violó y la dejó botada. Eso pasa todo el tiempo porque él se dedica a llevar gente para la capital. Ese señor vivía por allá donde el Barraco, ahora yo no sé donde vive. Es un haitiano, como de 25 años". 11. Para una discusión más detallada de los factores que contribuyen a la trata de mujeres haitianas, ver el estudio de OBMICA (2010). 
sus derechos; es así que se mueven en las arenas movedizas de la inseguridad ciudadana, agravada por el sesgo de género.

Las mujeres están en una situación de desventaja, entre otras razones, porque están en movimiento, por la violencia estructural que encuentran a su alrededor, y por la interseccionalidad de la opresión que encuentran. Dado que no se aborda de forma holística el problema de la violencia en ambas sociedades que habitan la isla, romper su círculo vicioso se hace muy difícil. En el contexto sui generis de esta franja fronteriza hay una variedad de perpetradores de violencia en su contra (mayormente hombres, tanto haitianos como dominicanos).

Según las entrevistas individuales cruzadas por dos grupos focales, las mujeres distinguen entre la violencia que se da en el contexto privado y la que se da en los ámbitos más públicos, como en el cruce de la frontera y en el mercado fronterizo. Según la socióloga haitiana, Magloire (2004), apoyándose también en los resultados de la última Encuesta de Hogares en Haití de 2000, la violencia doméstica está aceptada, incluso muchas veces está justificada. Kathia, una sobreviviente de la violencia doméstica (que tiene la transacción de pareja bien interiorizada), nos habla del maltrato en los siguientes términos:

Yo diría que si el hombre se va a trabajar y tú no cocinas para guardarle, no le lavas y estás cogiendo a otros hombres, yo diría que él pudiera tener derecho a darte golpes y a insultarte... (Él lo hacía) porque le gusta maltratar a las mujeres. Porque yo no le hice nada, no le he hecho lo malo (infidelidad). Cuando él sale encuentra la ropa lavada, cuando llega de trabajar yo cocino a las 12 y le guardo la comida. Yo diría que él piensa que la mujer no tiene ningún valor.

Agresiones cometidas por delincuentes o fuerzas armadas provocan más protestas que las cometidas por un ciudadano normal, según los grupos focales de este estudio, en los que hay risas más bien nerviosas al discutir las experiencias de relaciones sexuales impuestas por los maridos. ${ }^{12}$

Aunque las mujeres puedan no tener una conciencia plena de toda la gama de sus derechos, tienen un sentido de su dignidad personal (Tout

12. Coincide nuevamente con Magloire (2004).

\begin{tabular}{r|r}
2012 PRIMER SEMESTRE & 53 \\
\hline MIGRACIÓN Y DESARROLLO, VOL. 10, NO. 18 &
\end{tabular} 
moun se moun $)^{13} \mathrm{y}$ de su vulneración en la esfera pública. Las entrevistas con las mujeres son reveladoras de las actitudes sobre la mujer haitiana y el contexto sociocultural prevaleciente en los países vecinos. Ellas esperan que los hombres mantengan a la familia y que no les sean infieles; a cambio, aceptan lavarles la ropa y prepararles la comida, hacerse disponibles sexualmente, obedecerles (no andar en la calle) y ser respetables (no prostituirse). Las mujeres entrevistadas ven las relaciones como algo transaccional: si él quiere algo con ella, ella espera que le dé unos panties, por ejemplo, o algo para arreglarse el pelo.

Cuando se ven en una situación económica precaria, sin el apoyo de su marido, las mujeres haitianas a veces recurren a estrategias tales como esterilizarse (situación que es más factible en República Dominicana, debido a que el sistema de salud pública es más accesible que en Haití), prostituirse (en cuyo caso es más adecuada la zona de la frontera por la militarización y la mayor demanda que esto implica) o buscar otro hombre para que provea sustento económico (debido a que se amplían sus opciones por haber cruzado la frontera, puede ser dominicano). Estas estrategias no sólo resultan ineficaces para poner fin a la violencia económica que padecen en su vida cotidiana, sino que a veces suponen un riesgo mayor de sufrir otros tipos de violencia.

Para Daphnee, por ejemplo, no resultó efectiva la estrategia de juntarse con un dominicano para cubrir la manutención de sus hijos; la nueva pareja se negó a responsabilizarse por el niño cuando ella estaba embarazada y aun cuando nació el bebé. Actualmente se limita a pagar la renta de la casa que comparte con ella. Según Daphnee:

Estaba tan avergonzada porque cuando di a luz ni una ropita le compró al niño (...) Es en el hospital que me han regalado algunas cosas (...) Hasta ahora, él no le compra ropa al niño. Tengo otro niño conmigo y él no le compra nada, anda descalzo porque no tiene una chancletica para ponerse en los pies y yo no puedo trabajar porque este niño llora mucho. Le dije a él y a sus hijos que no me iba a quedar viviendo con él, que lo iba a dejar.

13. La traducción del creole haitiano es "Toda persona es una persona”. 
Sin embargo, Daphnee, que perdió su familia y su casa en el terremoto, no ha podido salir de su situación de violencia, porque no cuenta con ninguna ayuda y no tiene con quién dejar a sus hijos para salir a trabajar. También considera que soportar la violencia verbal y económica por parte de su pareja actual es preferible que el trabajo sexual forzado, al cual intentaron someterla las personas de la casa donde vivía al llegar a Comendador.

La provisión legal del "pago de la leche" fue establecida en República Dominicana en 2006, en la Ley 136-06, y en Haití en 2007, dentro de un menú legislativo promovido por el Ministerio para el Estatus de la $\mathrm{Mu}$ jer y los Derechos de la Mujer (MCFDF, por sus siglas en francés) (Wooding, Rivas y Séjour, 2008). A pesar de la existencia de estas medidas, la posibilidad de exigir derechos es muy vaga en un contexto institucional tan débil (tanto el haitiano como el dominicano); tal dificultad se acentúa profundamente en un país extranjero. Dadas estas circunstancias, es notable que las mujeres haitianas entrevistadas reconozcan y denuncien esta situación como violencia, y que comiencen a exigir sus derechos, aunque la falta de apoyo en la manutención sólo sea reconocida como vulneración de los derechos de sus hijos(as) y no una vulneración de su derecho de vivir una vida libre de violencia.

Las mujeres haitianas migrantes que se encuentran en la frontera y que logran salir de la casa para ayudar a sus familias se encuentran principalmente en tres lugares de trabajo, considerados como nichos laborales femeninos: en el mercado de Comendador, como vendedoras; en las casas de terceros, como trabajadoras domésticas; o en prostíbulos u otras casas de cita, en la prostitución. En cada uno de estos tres casos, y considerando su pobreza, el color de su piel y su estatus migratorio desfavorable, ${ }^{14}$ es clara su vulnerabilidad a los abusos por parte de los hombres, sea en el mercado fronterizo por cobradores (un nicho exclusivamente masculino), sea con sus clientes, en el ejercicio de la prostitución, o en la casa de terceros, donde muchas veces los varones asumen

14. Técnicamente, la nueva ley general de migración de 2004 en República Dominicana reconoce la figura de trabajador transfronterizo pero, como el reglamento para dicha ley está recién aprobado (octubre de 2011), este reconocimiento es algo académico ya que no tiene todavía aplicación en la práctica. 
que las domésticas deben acceder al acoso o violencia sexual. Por ejemplo, la violencia sexual es el tipo de violencia más común reportada por las trabajadoras domésticas en este estudio; ésta incluye el acoso sexual, la oferta de dinero para tener relaciones y la violación sexual, normalmente ejercida por el patrón o por algún miembro masculino de la familia que la emplea.

En Elías Piña, el trabajo doméstico es una de las principales opciones laborales para la mujer migrante. Según la explicación del Procurador Fiscal de esta provincia:

Han subido los costos en el servicio doméstico. Ahora un dominicano no trabaja tan fácil por 4,000 o 5,000 pesos. En cambio, la persona que está de paso, que está ilegal, tiende a ser más vulnerable en cuanto a los requerimientos como empleado. Por eso muchos prefieren la mano de obra extranjera ilegal, porque entienden que, por ejemplo, una mujer ilegal no le va a exigir pagar las prestaciones..$^{15}$

Por consiguiente, la extralegalidad crea las condiciones en que las trabajadoras migrantes pueden sufrir varios abusos. No sorprende, entonces, que las trabajadoras domésticas entrevistadas en este estudio, al igual que sus homólogas en otras partes del mundo, reportaran abusos de diverso tipo, entre ellos despido injustificado, retención del pago, salario muy por debajo del mínimo, jornada extendida, acusaciones de robo y, sobre todo, violencia sexual.

Incluso en los casos en que la trabajadora está acogida como "una más de la familia", la misma informalidad y las relaciones pseudoafectivas, especialmente con la patrona en la casa de la familia, pueden cohibir a la trabajadora a la hora de reivindicar sus derechos laborales o denunciar cualquier caso de abuso. En el caso de las trabajadoras domésticas haitianas, la invisibilidad de su trabajo, junto con su estatus migratorio e idiomático y el prejuicio contra ellas, hace que estén especialmente vulnerables en su espacio laboral (Wooding y Sangro, 2011).

15. Entrevista en la Fiscalía de Elías Piña, 18 de mayo de 2011. 


\section{LA RESPUESTA INSTITUCIONAL}

El sistema de referencia - lo que también se conoce como la "ruta crítica" - engloba todas aquellas instituciones y organizaciones que tengan la responsabilidad de prevenir o intervenir ante casos de violencia intrafamiliar y violencia contra las mujeres; este sistema establece los pasos que debe seguir una mujer que vive una situación de violencia para buscar atención, así como la respuesta institucional que recibe (Shader, 1998). Según la Ley 24-97, esta ruta inicia con la policía, pasa luego a la Fiscalía y a los médicos legistas para el apoderamiento de un tribunal. Sin embargo, esta ruta ha sido modificada por el Código del Procedimiento Penal.

En Elías Piña, el sistema de referencia involucra a varios actores estatales - Policía, Fiscalía, Hospital, Dirección Provincial de Salud y Oficina Provincial de la Mujer-y a algunos otros no estatales, como la CMS, la Red Fronteriza Jano Siksè y Plan Internacional. La gráfica 1 recoge la información levantada a través de las entrevistas y reuniones de trabajo en el marco de este estudio, sobre el funcionamiento actual del sistema de referencia en Elías Piña.

Adicionalmente, la CMS brinda acompañamiento legal y apoyo emocional a las sobrevivientes que acuden a su oficina. La Red Fronteriza Jano Siksè monitorea los casos de violaciones de derechos humanos y acompaña a la víctima en su búsqueda de una resolución del conflicto. Asimismo, Plan Internacional tiene un proyecto de prevención de la violencia intrafamiliar que consiste en impartir talleres de sensibilización en los barrios de Comendador, así como en otros municipios de Elías Piña. Los testimonios de las sobrevivientes entrevistadas confirman la decisión de muchas de no denunciar los actos violentos ejercidos en su contra. Algunos de los motivos derivados de la condición migratoria de las mujeres haitianas para no denunciar son los siguientes:

- No saben español (son recién llegadas);

- No conocen el sistema y, por lo mismo, no saben a dónde acudir;

- Creen que no tienen derechos porque son haitianas;

- Vienen de un contexto de institucionalidad muy débil, y 
- Temen ser repatriadas. Dicho temor se da tanto respecto de su propia repatriación (que, según la Fiscalía, no se hace), como de la repatriación de su agresor (que se hace en coordinación con la Dirección General de Migración y con el Cuerpo Especializado de las Fuerzas Armadas para el Control Fronterizo [Cesfront]).

\section{GRÁFICA 1}

Funcionamiento actual del sistema de referencia y contra-referencia en Elías Piña

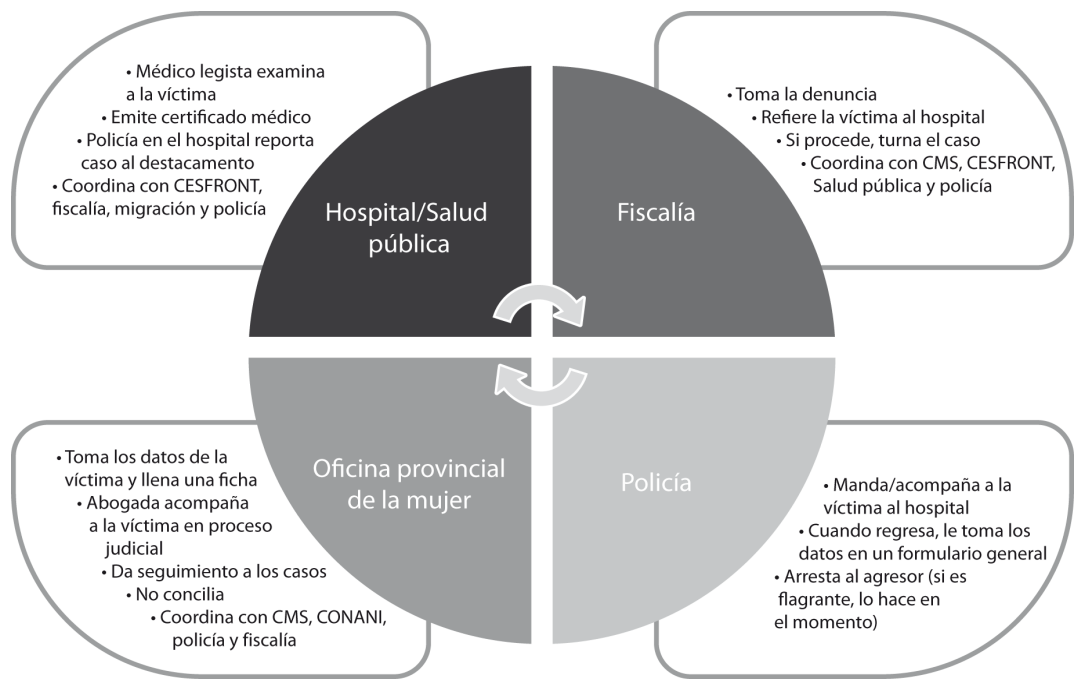

Tenemos el ejemplo de Nicole, una migrante de 25 años, que sufrió violencia doméstica a manos de su pareja, un nacional haitiano. Cuando llegó a Elías Piña nunca lo denunció, porque había llegado recientemente y no sabía hablar español. Dice que tampoco sabía a dónde ir, y que no tenía familia que la apoyara en el lugar. Otro ejemplo es el de Jorelyne, una trabajadora doméstica de 16 años, que no ha llegado a denunciar los abusos laborales ni el acoso sexual que ha sufrido por su empleador porque no sabe español y desconoce sus derechos laborales. Bibine tampoco denunció cuando su empleadora no le pagó porque cree que no tiene derechos por ser haitiana. Dice: "Yo no fui a la policía porque yo soy haitiana y ella es dominicana”. En situaciones de violencia, ellas simplemente cambian de empleo, con la esperanza de recibir un mejor trato en otra casa. 
En cuanto al temor a la repatriación, conviene señalar que las sobrevivientes no sólo temen por su propia repatriación sino también por la del agresor que, una vez repatriado, puede ser puesto en libertad. En el primer grupo focal, Kettia dijo: "Me gustaría saber (...) porque cuando un haitiano hace algo aquí, no lo llevan a la prisión, sino que lo llevan a Mibalen". Si consideramos que el coronel de Cesfront se ha manifestado sobre el hecho de que a veces no hay autoridades haitianas que reciban a las personas repatriadas (evidenciando con ello la débil institucionalidad en el país vecino), es viable concebir la deportación como un equivalente a la liberación incondicional del agresor. En estas circunstancias, se deja desprotegida a la denunciante ante posibles ataques en el futuro, puesto que, dada la porosidad de la frontera dominico-haitiana y la correspondiente facilidad con que entran y salen personas de ambos países, es muy probable que el agresor vuelva al territorio, frustrado por la deportación y con un deseo incrementado de "venganza" contra la denunciante.

Otras mujeres migrantes deciden no denunciar por motivos parecidos a los de las sobrevivientes dominicanas:

- Presión familiar y/o social;

- Creencia religiosa;

- "Desesperanza aprendida"; 16

- Temor del agresor;

- Dependencia económica, y

- Desconfianza en la capacidad de las instituciones para protegerlas o resolver la situación.

Mirlande, la migrante ${ }^{17}$ que sobrevivió 30 años de violencia sexual, verbal, económica y física, además de un intento de femicidio, nunca puso

16. Según Quiroga et al. (2009:83), la "desesperanza aprendida” (learned helplessness) es un estado de resignación en el que las mujeres víctimas de violencia se "dan por vencidas" y terminan asumiendo las agresiones como un castigo y destino ineludibles.

17. En casos como el del abuso extremo de Mirlande, cabe preguntar si se le puede considerar migrante o si más bien es una persona con un caso bien fundamentado para solicitar refugio. En algunos países, Mirlande podría solicitar asilo a causa de la persecución continua y las amenazas a su vida, junto con la ausencia de protección del Estado de donde se ha fugado. 
ninguna querella contra su esposo. Ella decidió no denunciar a causa del temor que sentía del agresor; también se sentía presionada por sus hijos, hasta que aceptó emigrar para vivir con uno de ellos, en lugar de denunciar ante las autoridades el abuso extremo que vivió. Según ella:

Yo no lo denuncié porque mis hijos no querían. Me dijeron: "si lo pones en la cárcel, la carga es para nosotros, él no tiene a nadie porque su familia es de la loma. Déjalo, cuando tú no puedas vivir con él, sácale el cuerpo. Cuando tú te levantes vas a tener un sentimiento de pena, y nosotros tendríamos que llevarle comida. Si tú ves que no puedes vivir con papá, déjalo y vete a vivir a la casa de una de tus hijas" (...) Tú sabes que cuando tienes hijos con una persona tú no corres para ir a la policía, porque hay una serie de cosas que esa persona te puede hacer, pero tú lo piensas y no entras a la justicia con esa persona (...) Hay un paquete de cosas que uno ve que podría hacerle (...) Tú no le haces una serie de cosas malas por tus hijos, porque mañana tus hijos van a ver lo que la mamá hizo.

Un factor agravante en cuanto a la respuesta institucional es la creciente militarización de la frontera, la cual se ha intensificado en los últimos años. En República Dominicana se estableció en septiembre de 2006, por decreto presidencial, un nuevo Cesfront que ha tenido resultado mixtos, causando cierta confusión en lo que respecta a sus responsabilidades y sus roles frente a los de las autoridades competentes de larga data en la zona. Del lado haitiano, la Misión de Estabilización de las Naciones Unidas en Haití (Minustah) - fuerza de estabilización de la Organización de las Naciones Unidas (ONU) - , ha ampliado su mandato en años recientes para tener más presencia en la frontera haitianodominicana, también con resultados mixtos. ${ }^{18}$ Además, de acuerdo con lo observado por el médico antropólogo Farmer (2003): por ser prácticamente los únicos hombres asalariados en algunas zonas de Haití, los

18. El pasado 28 de septiembre de 2011, el presidente haitiano, Michel Martelly, anunció planes para restaurar el Ejército ante la partida de la MINUSTAH, posiblemente en octubre de 2012. Si esto llega a ocurrir, la fuerza armada — de 3,500 hombres - tendría, indudablemente, presencia en la frontera, situación que impactaría también sobre la seguridad de las mujeres, las cuales, en lugar de beneficiarse de su protección, se convierten muchas veces en objeto de sus agresiones. 
militares se convierten en los focos de atención de las mujeres pobres que buscan mejorar su situación y la de sus familiares, en condiciones de asimetrías de poder que suelen ocurrir en este tipo de relaciones.

\section{CONCLUSIONES Y RECOMENDACIONES}

Las mujeres haitianas vienen de una cultura frágil, sobre todo en lo que se refiere a la exigibilidad de sus derechos. Las peripecias que enfrentan en su trayectoria migratoria dificultan el ejercicio de estas garantías en el país de destino, en parte porque no saben que son portadoras de derechos, pero también por la débil institucionalidad del Estado en República Dominicana.

La tabla 1 resume las tipologías identificadas de violencia que enfrentan las mujeres migratorias en el contexto fronterizo ComendadorBelladère.

En cuanto a la respuesta institucional, se analizaron tanto el sistema de referencia en casos de VCM como los esfuerzos en curso por mejorar la situación de violencia en el mercado y el cruce fronterizo. Se detectaron varias brechas y dificultades en lo que se refiere a la respuestas dadas en casos de VCM. Por una parte, la Fiscalía y la Policía reportan que las mujeres haitianas casi no denuncian, que dejan caer los casos y que es difícil localizar al agresor por la informalidad de las condiciones en que viven. Las mujeres entrevistadas reportan indiferencia y trato discriminatorio por la Policía. El Hospital y la Dirección Provincial de Salud se limitan a emitir el certificado médico a la mujer agredida; no intervienen para orientarla o referirla entre instituciones y tampoco levantan información estadística. Por último, la Oficina Provincial de la Mujer tiene muy poca proyección hacia la comunidad haitiana que, a su vez, desconoce la existencia de la misma. 
TABLA 1

Tipologías de VCM migrantes, en tránsito y desplazadas

\begin{tabular}{|c|c|c|c|}
\hline CONTEXTO & TIPO DE VIOLENCIA & PERPETRADORES & SOBREVIVIENTES \\
\hline Hogar & $\begin{array}{l}\text { Física, sexual, verbal, } \\
\text { económica }\end{array}$ & Pareja & $\begin{array}{l}\text { Haitianas (migrantes, } \\
\text { en tránsito y } \\
\text { desplazadas) }\end{array}$ \\
\hline $\begin{array}{l}\text { Cruce oficial: } \\
\text { Carrizal }\end{array}$ & $\begin{array}{l}\text { Cobro indebido de } \\
\text { "peaje", violencia física } \\
\text { y verbal, acoso sexual }\end{array}$ & Cesfront y guardias & Mujeres en tránsito \\
\hline $\begin{array}{l}\text { Cruce no oficial: } \\
\text { "por el monte" }\end{array}$ & $\begin{array}{l}\text { Robo, atraco, violencia } \\
\text { sexual, homicidio }\end{array}$ & $\begin{array}{l}\text { Buscones, acompañan- } \\
\text { tes, delincuentes, } \\
\text { motoristas }\end{array}$ & $\begin{array}{l}\text { Haitianas (migrantes, } \\
\text { en tránsito y } \\
\text { desplazadas) }\end{array}$ \\
\hline Calle & $\begin{array}{l}\text { Acoso y violación } \\
\text { sexual }\end{array}$ & $\begin{array}{l}\text { Hombres (conocidos } \\
\text { o desconocidos) }\end{array}$ & $\begin{array}{l}\text { Mujeres migrantes y } \\
\text { desplazadas }\end{array}$ \\
\hline Mercado & $\begin{array}{l}\text { Verbal, física, sexual, } \\
\text { "macuteo" }\end{array}$ & $\begin{array}{l}\text { Cobradores (los cua- } \\
\text { tro tipos), vendedores } \\
\text { y cobradores (física y } \\
\text { verbal) }\end{array}$ & $\begin{array}{l}\text { Comerciantes hai- } \\
\text { tianas }\end{array}$ \\
\hline $\begin{array}{l}\text { Trabajo } \\
\text { doméstico }\end{array}$ & $\begin{array}{l}\text { Vulneración de dere- } \\
\text { chos laborales, acoso } \\
\text { sexual, violación }\end{array}$ & $\begin{array}{l}\text { Empleadoras(es), } \\
\text { varones de la casa }\end{array}$ & $\begin{array}{l}\text { Trabajadoras } \\
\text { domésticas (migran- } \\
\text { tes y desplazadas) }\end{array}$ \\
\hline $\begin{array}{l}\text { Tráfico } \\
\text { y trata }\end{array}$ & $\begin{array}{l}\text { Engaño, violencia } \\
\text { sexual, trata }\end{array}$ & $\begin{array}{l}\text { Buscones, choferes, } \\
\text { autoridades cómplices }\end{array}$ & $\begin{array}{l}\text { Haitianas (migrantes, } \\
\text { en tránsito y } \\
\text { desplazadas) }\end{array}$ \\
\hline $\begin{array}{l}\text { Trabajo } \\
\text { sexual }\end{array}$ & $\begin{array}{l}\text { Trabajo sexual } \\
\text { forzado, robo }\end{array}$ & $\begin{array}{l}\text { Buscones, clientes, } \\
\text { autoridades cómplices }\end{array}$ & $\begin{array}{l}\text { Haitianas (migrantes, } \\
\text { en tránsito y } \\
\text { desplazadas), } \\
\text { en particular jóvenes }\end{array}$ \\
\hline Repatriaciones & $\begin{array}{l}\text { Vulneración al Proto- } \\
\text { colo Binacional de } \\
\text { Entendimiento (1999), } \\
\text { robo de pertenencias }\end{array}$ & $\begin{array}{l}\text { Cesfront } \\
\text { DGM }\end{array}$ & $\begin{array}{l}\text { Haitianas (migrantes, } \\
\text { en tránsito y } \\
\text { desplazadas) sospe- } \\
\text { chosas de estar en } \\
\text { situación irregular }\end{array}$ \\
\hline $\begin{array}{l}\text { Niñas y } \\
\text { adolescentes }\end{array}$ & $\begin{array}{l}\text { Maltrato en el hogar, } \\
\text { riesgo de abuso y explo- } \\
\text { tación, violencia sexual }\end{array}$ & $\begin{array}{l}\text { Integrantes de fa- } \\
\text { milias de acogida, } \\
\text { varones en casas de } \\
\text { acogida }\end{array}$ & $\begin{array}{l}\text { Hijas de crianza, } \\
\text { restavèk, jóvenes } \\
\text { desplazadas }\end{array}$ \\
\hline
\end{tabular}


Hay algunos esfuerzos en curso para mejorar la situación en el mercado y el cruce fronterizo. Destaca el trabajo actual de la Red Fronteriza Jano Siksè para convocar a las autoridades pertinentes y tomar medidas para mejorar la situación. Asimismo, hay esperanza de resolver varios problemas recurrentes a través de la construcción del nuevo mercado, pautado para los próximos años. Es de crucial importancia que las mujeres migrantes se organicen, con el apoyo de la sociedad civil, para que su voz y sus intereses sean escuchados y representados en las consultas acerca del nuevo proyecto.

Este estudio subraya la necesidad de un cambio radical en las prácticas actuales que toleran la violencia contra las mujeres migrantes en todas sus manifestaciones, señalando posibles pistas de acción para algunos actores clave, incluyendo a sus aliados en su trayectoria migratoria. Por último, cabe destacar que no es suficiente empoderar a las mujeres de cara a sus derechos, ni responsabilizar a los Estados aludidos en cuanto a sus obligaciones de mejorar la seguridad ciudadana, específicamente en relación a la violencia contra la mujer migrante en la franja fronteriza dominico-haitiana. Ante todo, compete a los Estados ingeniar otras oportunidades económicas para que las mujeres migrantes puedan enderezar las asimetrías de poder en las relaciones de género dadas en el hogar, en la calle y en su lugar de trabajo. También compete a los Estados firmar y ratificar el nuevo convenio 189 de la ONU de 2011, abogando por una agenda de trabajo decente para todos(as), con énfasis en las trabajadoras domésticas, y, en particular, las mujeres migrantes que trabajan en este oficio. 


\section{REFERENCIAS}

ACNur (6 mai 2010), Haiti Post Séisme 2010 les besoins en protection. Rapport de l'évaluation participative, Puerto Príncipe, Protection Cluster.

Castor, Suzy (1988), Le Massacre de 1937 et les relations haitianes-dominicaines, Haïti, CRESFED.

Dilla Alfonso, Haroldo y Sobeida de Jesús Cedano (2007), Frontera en transición. Diagnóstico multidisciplinario de la frontera dominico-haitiana, Grupo de Estudios Multidisciplinarios Ciudades y Fronteras, Santo Domingo.

Dilla Alfonso, Haroldo (2008), La apertura comercial transfronteriza: Oportunidades y obstáculos para el desarrollo local en la provincia de Elías Piña, Grupo de Estudios Multidisciplinarios Ciudades y Fronteras, Santo Domingo.

Farmer, Paul (2003), Pathologies of Power: Health, Human Rights and the New War on the Poor, University of California Press, Berkeley y Los Angeles.

FlaCso/ InEsa (2003), "Inventario de los conocimientos e intervenciones sobre la zona transfronteriza Haití-República Dominicana”, disponible en http:/taiguey.net/bohio.org//IMG/pdf/inofinal.pdf.

MAdre et al. (2010), "Our bodies are still trembling: Haitian Women's fight against rape", Boston, Institute for Justice and Democracy in Haiti (IJDH).

InterAction (2010), Lessons from the Haiti response and Recommended Next Steps. An analysis from Interaction's Gender-Based Violence Working Group, Washington, Policy Paper.

Lozano, Wilfredo (ed.) (1992), La cuestión haitiana en Santo Domingo. Migración internacional, desarrollo y relaciones interestatales entre Haití y República Dominicana, FLACSO-República Dominicana, Centro Norte-Sur Universidad de Miami, Santo Domingo.

Magloire, Danièle (2004), "La violence a l'égard des femmes: Une violation constante des droits de la personne", en Chemins Critiques, (V.2), Puerto Príncipe.

MuÑoz Cabrera, Patricia (2010), Violencias Interseccionales: Debates Feministas y Marcos Teóricos en el tema de Pobreza y Violencia contra las mujeres en Latinoamérica, Central American Women's Network (CAWN), Londres, disponible en http://www.cawn.org/assets/Violencias\%20Interseccionales.pdf.

Murray, Gerald F. (2010), Sources of Conflict along and across the HaitianDominican border, Panamerican Development Foundation, Santo Domingo, disponible en http:/web.clas.ufl.edu/users/murray/Research/Dominican_Republic/DomREP.index.htm. 
Pérez Orozco, A., D. Paiewonsky y M. García Domínguez (2008), Cruzando Fronteras II: Migración y Desarrollo desde una perspectiva de género, UN-INSTRAW, Santo Domingo.

Petrozziello, Allison J. y Bridget Wooding (2011), Fanm nan Fwontye, Fanm Toupatou: Una Mirada a la violencia contra las mujeres migratorias haitianas en tránsito y desplazadas en la frontera dominico-haitiana, Santo Domingo, CMs, Mujeres del Mundo, ОвмісA, Cies-Unibe.

Quiroga, L. et al. (2009), Sobre vivencias. Cuatro casos de violencia contra la mujer y su relación con el sistema de protección en Santo Domingo, InTEC y PNud, Santo Domingo.

Refugees International (2010), Haiti: From the Ground Up, Briefing report, Washington.

Shader, E. y Monserrat S. (1998), "Violencia contra la mujer", Protocolo de Investigación, Organización Panamericana de Salud, Washington.

Silié, Ruben y Carlos Segura (eds.) (2002), Memorias del Seminario Internacional. Hacia una nueva visión de la frontera y las relaciones fronterizas, Flacso, Santo Domingo.

Toupin, Sophie (coord.) (2010), Ensuring Women's Participation and Leadership in all Stages of National Relief and Reconstruction, A Gender Shadow Report of the 2010 Haiti Post-Disaster Needs Assessment.

Wooding, Bridget y Alicia Sangro (2011), "La presencia de las mujeres migrantes haitianas en el servicio doméstico en la República Dominicana”, en Roberto E. Liz (ed.), Movimientos Migratorios desde y hacia República Dominicana, Tomo 1, Santo Domingo, Ministerio de Economía, Planificación y Desarrollo, FiEs.

Wooding, Bridget, Eddy Tejeda, Cristina Santillán Idoate, Jonathan Boyer (2010), Mujeres en el Camino: La trata de mujeres haitianas en República Dominicana tras el terremoto en Haití, Obmica, Flacso, Cies-Unibe, Oim, Santo Domingo.

Wooding, Bridget, M. Rivas y S. Séjour (2008), On the Cusp of Change. Addressing the challenges for aid effectiveness and gender justice in Haiti. Mapping report, UNIFEM, Haiti and Caribbean region. 
